\title{
Okul Yöneticilerinin Analitik ve Bütüncül Düșünme Tarzlarına Göre Çatışma Eylem Stillerinin İncelenmesi
}

\author{
Tuba AKPOLAT', Ebru OĞUZ²
}

\begin{abstract}
Öz: Bu çalışmada okul yöneticilerinin analitik ve bütüncül düşünme tarzlarına göre çatışma çözme stilleri incelenmektedir. Betimsel nitelikte olan bu çalışmada ilişkisel tarama modeli kullanılmıştır. Araştırmanın çalışma grubunu 2020-2021 öğretim yılında İstanbul İli Avcılar ve Bakırköy ilçelerinde çalışan uygun örnekleme ile belirlenmiş 183 okul yöneticisi oluşturmaktadır. Çalışmada veri toplama aracı olarak Çatışma Eylem Stilleri Ölçeği ile Analitik ve Bütüncül Düşünme Ölçeği kullanılmıştır. Çalışmanın sonucunda okul yöneticilerinin çoğunun bütüncül düşünme stiline sahip oldukları, okul yöneticilerinin en çok kullandığı çatışma eylem stilinin kolaylaştırıcı çatışma eylem stili olduğu, bütüncül düşünen okul yöneticilerinin analitik düşünen okul yöneticilerine göre daha çok kolaylaştırıcı ve uzlaştırıcı çatışma çözme eylem stillerini kullandıkları görülmüştür.
\end{abstract}

Anahtar Sözcükler: Analitik Düşünme, Bütüncül Düşünme, Çatışma Çözme Stilleri

\section{Examination of Conflict Action Styles According to School Administrators' Analytical and Holistic Thinking Styles}

\begin{abstract}
This study examines the conflict resolution styles of school administrators according to their analytical and holistic thinking styles. The relational screening model was used in this descriptive study. The study group of the research consists of 183 school administrators, who were determined by convenience sampling, working in the Avcrlar and Bakırköy districts of Istanbul, Turkey in the 2020-2021 academic year. Conflict Action Styles Scale and Analytical and Holistic Thinking Scale were used as data collection tools in the study. The results of the study reveal that most of the school administrators have a holistic thinking style, the conflict action style most used by school administrators is the facilitating conflict action style and the school administrators with holistic thinking use more facilitating and conciliatory conflict resolution action styles than the analytical thinking school administrators.
\end{abstract}

Keywords: Analytical Thinking, Holistic Thinking, Conflict Resolution Styles

${ }^{1}$ Mimar Sinan Güzel Sanatlar Üniversitesi, Fen Edebiyat Fakültesi, Eğitim Bilimleri Bölümü, İstanbul, Türkiye, tuba.sagir.akpolat@msgsu.edu.tr., ORCID: https://orcid.org/0000-0001-5907-6972

2 Mimar Sinan Güzel Sanatlar Üniversitesi, Fen Edebiyat Fakültesi, Eğitim Bilimleri Bölümü, İstanbul, Türkiye, ebru.oguz@msgsu.edu.tr., ORCID: https://orcid.org/0000-0002-5731-011X

\section{Atıf için/ To cite:}

Akpolat, T. Oğuz, E. (2022). Okul yöneticilerinin analitik ve bütüncül düşünme tarzlarına göre çatışma eylem stillerinin incelenmesi. Yaşadıkça Ĕ̆itim, 36(1), 35-50. 
Türkiye'de okul yöneticileri okul müdürü ve okul müdür yardımcıları olarak görev yapmaktadır. Okul yöneticileri, görev tanımları gereği birçok rol ve sorumluluk üstlenmektedirler. Okul yöneticilerinden yalnızca okullarını yönetmek değil aynı zamanda çağın gereğine uygun değişikliklere de liderlik etmeleri beklenmektedir. Değişimin olduğu yerde de çatışmanın olacağı aşikardır. Örgüt içinde farklı değerleri ile insanlar birbirleriyle etkileşim içinde olduklarında ortaya gerilim yaratan durumlar çıabilmektedir. Dolayısıyla çatışma bir örgüt içinde çalışan iki ya da daha fazla kişinin anlaşamadığı bir durum olarak görülür (Darling ve Walker, 2001). Okul yöneticilerinin çatışma çözme yaklaşımları, okulu amacına uygun yönetirken, oluşturmaları gereken ekip ruhunu korumaları açısından önem taşımaktadır. Her örgütte olduğu gibi eğitim örgütlerinde de kişilerarasında çeşitli nedenlerle çatışmalar çıkmaktadır. Bir örgütte çatışmaya neden olabilecek bazı sorunları Anthony ve diğerleri (2010); iletişim (iletişimsizlik), çalışan tutumları, dürüstlük, itaatsizlik, başkalarına edilen muamele ve çalışma alışkanlıkları şeklinde sıralamıştır. Bunlar ve bunlara benzer birçok durumda okul yöneticileri farklı bir çatışma çözme yaklaşımı sergileyebilmektedir.

Çatışma genellikle kararsızlık, kabul edememe gibi düşünce durumları ile öfke, kavga gibi birçok duygu ve davranış durumlarının varlığı ile ilişkilendirilir. Üstelik gündelik yaşamın ve iletişimin o kadar doğal bir bileşenidir ki çoğu zaman üzerinde düşünülmeden, analiz edilmeden ve incelenmeden yaşanılır (Shapiro ve diğerleri, 2004). Çatışma, kişinin sözlerini veya değerlerini yanlış yorumlamaktan kaynaklanabilir. Çatışma, uygunsuz, kötü iletilen bilgiler ve bilgilerin iletilmesi için yanlış kanalın seçilmesi durumunda ortaya çıkmaktadır (Huan ve Yazdanifard, 2012). Çatışma, kişilerarası ya da gruplar arası etkileşimde, her bir birey ya da grubun karşı tarafın görüşlerini kabul etmeye çalışma sürecinde ortaya çıkan anlaşmazlık olarak tanımlanabilir (Thakore, 2013). Yaşamın akışında genel olarak çatışma, önlenmesi gereken ve önlenmediğinde zararlı sonuçlara neden olan bir durum olarak görülmektedir. Fakat çatışma çözme temelde bir problem çözme durumudur ve bir süreç anlamına gelmektedir (Burton, 1990). Dolayısıyla çatışmanın varlığı her zaman yıkıcı sonuçların ortaya çıkacağı anlamına gelmemektedir. Bu noktadan hareketle çatışma yıkıcı ve yapıcı olarak birbirinden ayrılır. Deutsch (1973) yıkıcı çatışmayı, çatışmanın odak konusunun dışına çıkarak onunla bağlantılı diğer konulara sıçraması, tehdit ve zorlayıcı stratejilerin işe koşularak çatışmanın sonuçlandırılmaya çalışılması ve sonuçta her iki tarafın memnuniyetsizliği ile sonuçlanan "kaybet-kaybet" tarzı çözümün ortaya çıkması ile tanımlar. Yapıcı çatışmayı ise problemin çözüm süreci boyunca tarafların ana konuya odaklanmaya devam etmesi ve her iki taraf için de tatmin edici sonuçlara ulaşılması için iş birliğinin kabul edilmesi ve sonuçta "kazan-kazan" tarzı bir çözümün ortaya çıkması olarak tanımlar.

Bir çatışmanın çözülmesini etkileyen birçok parametre vardır. Bunlardan bazıları kişilik özellikleri (Karakuş ve Çankaya, 2009), duygusal zekâ (Özdemir ve Özdemir, 2007), öz yeterlilik algısıdır (İnandı, Tunç ve Gündüz, 2013). Bununla birlikte bir çatışmanın çözümünde inançlar, tutumlar ve değerlerdeki benzerliklerin çatışmanın nispeten daha sorunsuz çözülmesine ya da çatışma durumlarının azaltılmasında olumlu etkisinin olduğu söylenmektedir (Berscheid ve diğerleri, 1969). Çatışma çözmede yaygın olarak kullanılan birkaç yol vardır. Bunlar kaçınmacı, zorlayıcı, kolaylaştırııı, uzlaştırıcı ve karşı koyucu çatışma çözme eylem stilleridir (Karadağ ve Tosun, 2014). Çatışma çözmede kaçınmacı stili tercih edenler, çatışmayı görmezden gelme eğilimindedir (Rahim ve diğerleri, 2001). Kaçınmacı stilin, ilişkinin sürdürülmesini odağa koyan Doğu Asya kültüründe yaygın olduğu söylenmektedir (Huang, 1999). Lussier'e (2010) göre kaçınmac1 stilin olumlu tarafı ilişkilerin sürdürülebilirliğinin sağlanması iken olumsuz tarafı çatışmanın çözülememiş olmasıdır. Zorlayıcı çatışma eylem stili, hedeflere ulaşmak için otoriteleri, tehditleri vb. kullanarak karşı tarafı anlaşmaya (boyun eğmeye) zorlamayı içermektedir (Lussier, 2010). Kolaylaştırıcı çatışma eylem stili, ilişkilere zarar vermemek ve sürdürülebilir ilişkiler için kişisel amaç ve çıkarlarından fedakârlık etmeyi içermektedir (Öksüz ve Öztürk, 2016). Uzlaştırıcı çatışma eylem stili, ortak bir noktada buluşabilmek adına çatışmaya dahil olan her tarafın bir şeyden vazgeçeceği bir alı̧̧-veriş durumunu içermektedir (Yuan, 2007). Karşı koyucu çatışma eylem stili, çatışmanın yararını ortaya çıkarmak için çatışma sırasında amaçlara ve ilişkilere değer vererek, çatışmaya dahil olan her iki tarafın yararına olan çözümleri araştırmayı içermektedir (Mızrak, 2019).

Çatışma çözmede kullanılan yöntemlere etki eden birçok faktörden biri de kültürdür. Çatışma çözmenin kültürel olarak öğrenildiği belirtilmektedir (Hammer, 2005). Kültür aynı zamanda bireylerin düşünme biçimlerini de etkilemektedir. İnsanların düşünme biçimleri, içinde yaşadıkları sosyal çevreden 
büyük oranda etkilenir. Bazı çevrelerde yaşamak, az sayıda insanla ömür boyu sürecek ilişkileri sürdürmeyi içerirken, bazıları birçok insanla kısa ve geçici sosyal etkileşimleri içerebilir (San Martin ve diğerleri, 2019). Hayatın içinde deneyimlenen her yaşantı bireylerin düşünme tarzlarına etki edecektir. Kültürün düşünce tarzını etkilediği, bireyci kültürlerde yetişmiş bireylerin analitik düşünme tarzına ve toplumcu kültürlerde yetişmiş bireylerin ise bütüncül düşünme tarzına sahip olduğunu belirtilmektedir (Choi ve diğerleri, 2007; Nisbett ve diğerleri, 2001).

Bütüncül düşünme, toplumsallık kültürünün yoğun yaşandığı Doğu Asya kültürüne atfedilir. Bütüncül düşünme, odak nesnesi ile bu nesnenin içinde bulunduğu alan arasındaki ilişkilere dikkat ve olayları bu tür ilişkileri dikkate alarak açıklama ve tahmin etmeyi içeren, bir bütün olarak olayı bağlam içinde değerlendiren bir düşünme yönelimidir (Nisbett ve diğerleri., 2001). Bütüncül düşünen bireylerin temel özelliği, olayları ve nesneleri sunuldukları bağlamda değerlendirme eğilimidir. Dünyayı etkileşimlerin, ilişkilerin ve tüm değiş tokuşların karmaşık yapısı olarak görme, olaylar arasındaki bağlantılara dikkat etme bütüncül bakış açısıyla yaklaşılan bir konunun çözümünde düşünülen unsurlardır (Apanovich ve diğerleri, 2018).

Analitik düşünme ise bireysellik kültürünün ön planda olduğu Batı kültürüne atfedilir. Analitik düşünme, odak konusu olan nesnenin bağlamından koparılarak, söz konusu nesneye ilişkin özellikler dikkate alınarak, kategorilere atama eğilimi ve nesnenin davranışını kategorilere ilişkin kuralları kullanarak açıklama ve tahmin etme eğilimini içeren düşünme tarzıdır (Nisbett ve diğerleri, 2001). Dolayısıyla analitik düşünme tarzına sahip bireyler, dünyanın ayrı ve süreksiz olduğuna ve bir nesnenin davranışının kurallar ve özellikler kullanılarak tahmin edilebileceğine dair inançlara sahiptirler (Monga ve John, 2007). Bu bakımdan bütüncül düşünme tarzına sahip bireylerin aksine analitik düşünenler, olayları ve nesneleri çevreleriyle etkileşimden ziyade öncelikle kendi kurallarına göre değişen ve zaman içinde değişmez görme eğilimindedir (Nisbett ve Masuda, 2003).

Epstein (1994) bir kişilik teorisi olarak ortaya koyduğu bilişsel deneyimsel teoride, iki farklı düşünme (bilgi işleme) sistemi olduğunu belirtmektedir: akılcı ve deneyimsel. Akılcı (rasyonel) sistem, bir kişinin kültürel olarak aktarılan, akıl yürütme kuralları anlayışıyla işleyen çıkarımsal bir sistemdir. Akılcı sistem bilinçli, görece yavaş, analitik, öncelikle sözlü ve çok kısa bir evrimsel geçmişe sahiptir. Deneyimsel sistem ise, önceden bilinçli, hızlı, otomatik, bütünsel, öncelikli olarak sözsüz, duygulanımla yakından ilişkili ve çok uzun bir evrimsel geçmişe sahip bir öğrenme sistemidir. Deneyimsel ve rasyonel düşünme sistemleri arasındaki fark Tablo 1'de gösterilmektedir.

Tablo 1. Deneyimsel ve Rasyonel Düşünme Sistemleri Karşılaştırması*

\begin{tabular}{|c|c|}
\hline Deneyimsel Sistem & Rasyonel Sistem \\
\hline 1. Bütüncül & 1. Analitik \\
\hline Otomatik, zahmetsiz & Kasitll, çaba gerektiren \\
\hline Duyuşsal: Zevk-acı odaklı (iyi hissettiren) & Mantıksal: Akıl odaklı (mantıklı olan) \\
\hline 4. İlişkisel bağlantılar & 4. Mantıksal bağlantılar \\
\hline $\begin{array}{l}\text { 5. Geçmiş deneyimlerden gelen "titreşimlerin" aracılık } \\
\text { ettiği davranış }\end{array}$ & $\begin{array}{l}\text { 5. Olayların bilinçli değerlendirilmesinin aracılık ettiği } \\
\text { davranış }\end{array}$ \\
\hline $\begin{array}{l}\text { 6. Gerçekliği somut görüntüler, metaforlar ve anlatılarla } \\
\text { kodlar }\end{array}$ & $\begin{array}{l}\text { 6. Gerçeği soyut semboller, kelimeler ve sayılarla } \\
\text { kodlar }\end{array}$ \\
\hline 7. Daha hızlı işleme: Anında eyleme yöneliktir & 7. Daha yavaş işleme: Gecikmiş eyleme yönelme \\
\hline $\begin{array}{l}\text { 8. Değişmesi daha yavaş: Tekrarlayan veya yoğun } \\
\text { deneyime bağlı değişiklikler }\end{array}$ & $\begin{array}{l}\text { 8. Daha hızlı değişme: Düşünme hızıyla değişme } \\
\text { 9. Daha çok farklılaşmış }\end{array}$ \\
\hline $\begin{array}{l}\text { 9. Daha kabaca farklılaştırılmış: Geniş genelleme } \\
\text { gradyanı- stereotipik düşünme }\end{array}$ & $\begin{array}{l}\text { 10. Daha yüksek düzeyde entegre: Bağlamlar arası } \\
\text { işleme }\end{array}$ \\
\hline $\begin{array}{l}\text { 10. Daha kabaca entegre: Çözülme, duygusal } \\
\text { kompleksler; bağlama özgü işleme }\end{array}$ & $\begin{array}{l}\text { 11. Aktif ve bilinçli olarak deneyimlendi: } \\
\text { Düşüncelerimizin kontrolü bizde }\end{array}$ \\
\hline $\begin{array}{l}\text { 11. Pasif ve bilinçli olarak deneyimlendi: Duygularımız } \\
\text { tarafından ele geçirildik } \\
\text { 12. Açıça geçerli: "Deneyimlemek inanmaktır." }\end{array}$ & 12. Mantık ve kanit yoluyla gerekçelendirme gerektirir \\
\hline
\end{tabular}

Tablo 1'de gösterildiği gibi deneyimsel düşünme sistemi, duygulardan ve geçmiş yaşantılardan etkilenen, hızlı, otomatik, bütüncülken; rasyonel düşünme sistemi mantık odaklı, daha yavaş ve analitiktir. 
Dolayısıyla bütünsel düşünme stili deneyim odaklı iken, analitik düşünme stili bilişsel odaklıdır denebilir.

Baskın olarak analitik ya da bütünsel düşünen bireyler, davranışın bağlamsal nedenlerini görmezden gelme ya da bağlama odaklanma gibi birbirine tezat iki uç düşünme stilinde birbirinden farklı kararlar vermektedirler. Örneğin öğrenci başarısı konusunda bütüncül düşünürler çabanın (bağlamsal bir faktör) önemli olduğuna inanırlarken, analitik düşünürler öğrencinin içsel, doğal yeteneklerinin daha fazla etkiye sahip olduğuna inanırlar (Stevenson ve Stigler, 1992). Analitik ve bütüncül düşünme stilleri aslında farklı kültürlerde, farklı sosyal ortamların insanların düşünme tarzını etkilediği varsayımına dayanarak ortaya atılmış olmasına rağmen aynı kültürde yaşayan insanlar arasında da düşünme tarzında bu tür bir farklılık olabileceği yapılan çalışmalarda ortaya konulmuştur (Kavak ve diğerleri, 2016; Umay ve Arıol, 2011).

İnsanlar çatışmalara kültürleri tarafından öğretilen, izin verilen veya yönetilen bir yönde yaklaşırlar (Alagözlü, 2017). Kültür aynı zamanda, insanların düşünme biçimlerine etki eden önemli faktörlerden biridir. $\mathrm{Bu}$ durumda bir okul yöneticisinin, herhangi bir çatışma durumuna yönelik takınacağı tutum ve yaklaşımlarda, okul yöneticilerinin düşünme stillerinin de etki edeceği söylenebilir. Bununla birlikte düşünme stilleri bireylerin karar alma ve problem çözme eğilimlerini etkilemektedir (Tekin ve diğerleri, 2009). Çatışma çözme de temelde bir problem çözme yaklaşımı olduğundan dolayı bireylerin düşünme stilleri ile çatışma çözme stilleri arasında bir ilişki olacaktır (Rafique ve diğerleri, 2020). Söz konusu problemin çözümü için elde edilen verilere ya da sezgilere dayanarak alınan rasyonel ya da irrasyonel kararlar, bir düşünme stilinin çıtıları olarak problemin çözülmesine katkı sağlayacaktır. Okul yöneticilerinin baskın olarak hangi düşünme stilini benimsedikleri ile çatışma çözmede kullandıkları yöntemlerin hangileri olduğu ve düşünme stilleri ile çatışma çözme yöntemleri arasındaki ilişkilerin ne düzeyde ve yönde olduğunu anlamak, okul yöneticilerinin çatışma çözmeye bakış açılarını ortaya koymak adına önem taşımaktadır. Bu bağlamda temel amacı okul yöneticilerinin çatışma eylem stilleri ile düşünme tarzları arasındaki ilişkinin incelenmesi olan bu araştırmada aşağıdaki sorulara cevap aranmıştır:

Araştırma sorusu 1. Okul yöneticilerinin düşünme tarzları ve çatışma eylem stilleri demografik özelliklerine göre farklılık göstermekte midir?

Araştırma sorusu 2. Okul yöneticilerinin çatışma eylem stilleri düşünme tarzlarına göre farklılaşmakta midir?

Araştırma sorusu 3. Okul yöneticilerinin düşünme tarzları ile çatışma eylem stilleri arasında bir ilişki var midır?

\section{Yöntem}

Okul yöneticilerinin düşünme tarzları ile çatışma eylem stilleri arasındaki ilişkilerin incelendiği bu araştırma ilişkisel tarama modelinde tasarlanmıştır. Illişkisel tarama modelinde, iki ya da daha çok değişkenin birlikte değişim varlığı ve/veya derecesi belirlenmeye çalışılır (Karasar, 2003).

\section{Evren ve Örneklem}

Araştırmanın çalışma evrenini İstanbul İli Avcılar ve Bakırköy ilçelerinde çalışan 135 okul müdürü ve 244 okul müdür yardımcısı oluşturmaktadır. COVID 19 salgını nedeniyle çalışma örneklemi uygun örnekleme yöntemiyle belirlenmiştir. Çalışmanın örneklemini 183 okul yöneticisi oluşturmaktadır. Örnekleme ilişkin demografik özellikler Tablo 2'de gösterilmiştir.

Tablo 2. Demografik Özellikler

\begin{tabular}{llll}
\hline Demografik değişken & Kategori & $\mathbf{N}$ & $\mathbf{\%}$ \\
\hline \multirow{2}{*}{ Cinsiyet } & Kadın & 61 & $\% 34$ \\
& Erkek & 122 & $\% 67$ \\
\hline \multirow{3}{*}{ Kıdem } & $1-5$ yıl & 54 & $\% 30$ \\
& $6-10$ yıl & 44 & $\% 24$ \\
& $11-15$ yıl & 31 & $\% 17$ \\
& $16-20$ yıl & 25 & $\% 13$ \\
\hline
\end{tabular}




\begin{tabular}{|c|c|c|c|}
\hline \multirow{3}{*}{ Okul Türü } & İlkokul & 66 & $\% 36$ \\
\hline & Ortaokul & 51 & $\% 28$ \\
\hline & Lise & 66 & $\% 36$ \\
\hline \multirow[t]{2}{*}{ Görev } & Okul Müdürü & 92 & $\% 51$ \\
\hline & Müdür Yardımcısı & 91 & $\% 49$ \\
\hline
\end{tabular}

Çalışmanın örneklemini oluşturan okul yöneticilerinin 61'i kadın (\%34), 122'si erkek (\%67); 54'ü 1-5 yıl kıdeme sahip (\%30), 44' ü 6-10 yıl kıdeme sahip (\%24), 31'i 11-15 yıl kıdeme sahip (\%17), 25'i 16-20 yıl kıdeme sahip (\%13), 29'u 21 ve üzeri kıdeme sahiptir (\%16). Bununla birlikte okul yöneticilerinin 66'ss ilkokulda (\%36), 51'i ortaokulda (28), 66'sı lisede (\%36) görev yapmakta ve 92'si okul müdürü (\%51), 91'i okul müdür yardımcısı (\%49) olarak görev yapmaktadır.

\section{Veri Toplama Araçları}

Araştırmada veri toplama aracı olarak Çatışma Eylem Stilleri Ölçeği ile Analitik ve Bütüncül Düşünme Ölçeği kullanılmıştır.

Çatışma Eylem Stilleri Ölçeği Tracy ve Johnson (1981) tarafından geliştirildikten sonra 2008 yılında yine Johnson ve Johnson (2008) tarafından revize edilmiştir. Ölçek Karadağ ve Tosun (2014) tarafından Türkçe'ye uyarlanmıştır. Beşli likert tipinde tasarlanan ölçek 35 madde ve 5 alt boyuttan oluşmaktadır. Bu alt boyutlar kaçınmacı, karşı koyucu, uzlaştırmacı, zorlayıcı ve kolaylaştırıcı olarak isimlendirilmiştir. Alt boyutlara ilişkin güvenilirlik katsayıları sırasıyla $\alpha=.79, \alpha=.76, \alpha=.77, \alpha=.78$ ve $\alpha=.72^{\prime}$ dir.

Analitik ve Bütüncül Düşünme Tarzı Ölçeği Choi (2003) tarafından geliştirilmiş ve Kavak ve diğerleri (2017) tarafından Türkçe'ye uyarlanmıştır. Ölçek 8 sorudan oluşmaktadır. Güvenilirlik katsayısı $\alpha=.74$ 'tür. Örnekleme ilişkin düşünme tarzı skor ortalamasının altında bir puana sahip olunması analitik düşünme tarzına ve üstünde bir puana sahip olunması ise bütüncül düşünme tarzına sahip olunduğu anlamına gelmektedir.

\section{Verilerin Toplanması ve Analizi}

Veri toplama araçları ile toplanan veriler SPSS24 istatistik programına işledikten sonra veri toplama araçlarının güvenilirliğini analiz edilebilmesi için Cronbach's Alpha iç tutarlılık katsayısı hesaplanmıştır. Analiz sonucunda çatışma eylem stilleri ölçeği alt boyutlarından kaçınmacı, zorlayıcı ve karşı koyucu çatışma eylem stillerinin iç tutarlılık katsayısının $\alpha=.70$ olduğu ve kolaylaştırıcı ile uzlaştırmacı çatışma eylem stilleri alt boyutlarının iç tutarlılık katsayısının $\alpha=.72$ olduğu görülmüştür. Bununla beraber düşünme tarzı ölçeğinin içi tutarlılık katsayısının $\alpha=.91$ olduğu görülmüştür. İç tutarlılık katsayısının .70'ten büyük olması veri toplama araçlarının güvenilir olduğunun göstergesidir (Karasar, 2003).

Veri setinin analizinde hangi analiz tekniklerin kullanacağına karar verebilmek için veri setinin normallik varsayımını sağlama durumunu analiz etmek için her bir alt boyuta ilişkin basıklık ve çarpıklık değerlerine bakılmıştır. Basıklık ve çarpıklık değerlerinin -1 ile +1 arasında olması veri setinin normallik varsayımını sağladığını söylemek için yeterli görülmektedir (Tabachnick ve Fidell, 2013). Çatışma eylem stilleri ölçeği alt boyutlarından kaçınmacı çatışma eylem stilinin (basıklık=-.071; çarpıklık=-.169), zorlayıcı çatışma eylem stilinin (basıklık=571; çarpıklık=-.171), kolaylaştırıcı çatışma eylem stilinin (basıklık=.443; çarpıklık=-.361), uzlaştırmacı çatışma eylem stilinin (basıklık=.666; çarpıklık=-.565) ve karşı koyucu çatışma eylem stilinin (basıklık=.975; çarpıklık=-.615) normallik varsayımı için kabul edilen aralıkta değerler aldığı görülmüştür. Bununla birlikte düşünme tarzı ölçeğinin (basıklık=5.29; çarpıklık=-2.05) değerlerinin ilgili aralıkta olmadığı görülmüştür. Dolayısıyla veri setinin analizinde parametrik ve non-parametrik teknikler kullanılmıştır.

SPSS24 istatistik programı kullanılarak, katılımcıların demografik değişkenlerine göre çatışma eylem stillerindeki karşılaştırmalar için bağımsız gruplar $t$ testi ile tek yönlü ANOVA testi kullanılmıştır. Katılımcıların demografik değişkenlerine göre düşünme tarzındaki karşılaştırmalar için Mann Wihtney U ve Kruskall Wallis testleri kullanılmıştır. Bununla birlikte, Düşünme Tarzı ölçeğinden alınan ortalama puanın altında kalan katılımcıların analitik ve üstünde kalan katılımcıların bütüncül düşünme tarzına sahip olarak 
kodlanmaları, bu değişkenin yapay süreksiz değişken olmasını sağlamıştır. Katılımcıların düşünme stillerine göre çatışma eylem stilleri ortalamalarını karşılaştırmak için bağımsız gruplar $t$ testi kullanılmış ve değişkenler arasındaki istatistiksel ilişkinin gücünü analiz etmek için Cohen's d etki değeri büyüklüğü hesaplanmıştır. Cohen d değerinin .2' den küçük olması etki büyüklüğünün zayıf, .5 olması etki büyüklüğünün orta ve .8'den büyük olması etki büyüklüğünün yüksek olduğu anlamina gelmektedir (Kılıç, 2014). Bununla birlikte düşünme tarzı ile çatışma eylem stilleri arasındaki ilişki Pearson çarpım moment korelasyon katsayısı ile incelenmiştir.

\section{Bulgular}

Okul yöneticilerinin çatışma eylem stili ve düşünme tarzı ölçeklerine verdikleri cevaplara ilişkin ortalama puan ve standart sapma değerleri Tablo 3'te gösterilmiştir.

Tablo 3. Okul Yöneticilerinin Çatışma Eylem Stilleri ve Düşünme Tarzı Ortalama Puan ve Standart Sapmaları

\begin{tabular}{lcc}
\hline Ölçekler & $\overline{\boldsymbol{X}}$ & SS \\
\hline Kaçınmacı & 2.80 & .68 \\
Zorlayıcı & 3.36 & .63 \\
Kolaylaştırıcı & 3.87 & .57 \\
Uzlaştırmacı & 3.42 & .64 \\
Karşı koyucu & 3.68 & .60 \\
Düşünme Stili & 4.04 & .83 \\
\hline
\end{tabular}

Tablo 3 incelendiğinde okul yöneticilerinin kaçınmacı çatışma eylem stilini “kararsızım” düzeyinde $(\bar{X}=$ 2.80), zorlayıcı çatışma eylem stilini "kararsızım" düzeyinde $(\bar{X}=3.36)$, kolaylaştırıcı çatışma eylem stilini "katılıyorum" düzeyinde $(\bar{X}=3.87)$, uzlaştırmacı çatışma eylem stilini "katılıyorum" düzeyinde $(\bar{X}=3.42)$ ve karşı koyucu çatışma eylem stilini "katılıyorum" düzeyinde $(\bar{X}=3.68)$ kullandıkları görülmektedir. Bu bulguya göre okul yöneticilerinin en yüksek düzeyde kolaylaştırıcı çatışma eylem stilini kullandıkları görülmektedir. Bu durum okul yöneticilerinin çatışmaları kendi çıkarlarından tavizler vererek çözmeyi yeğledikleri anlamı taşımaktadır. Bununla birlikte okul yöneticilerinin düşünme stilleri ortalama puanının $\bar{X}=4.04$ olduğu görülmektedir. Bu durum okul yöneticilerinin düşünme stili ortalamasının söz konusu ortalamadan düşük olması durumunda analitik düşünme stiline sahip oldukları ve yine bu ortalamadan yüksek ortalama puana sahip olması durumunda bütüncül düşünme stiline sahip oldukları anlamını taşımaktadır.

Okul yöneticilerinin cinsiyetlerine ve yaptıkları görevlere göre düşünme stilleri arasındaki fark Mann Wihtney $\mathrm{U}$ t testi ile analiz edilerek ilgili sonuçlar Tablo 4 'te gösterilmiştir.

Tablo 4. Okul Yöneticilerinin Cinsiyet ve Görevlerine göre Düşünme Stilleri Puanlarının Karşılaştırılması

\begin{tabular}{|c|c|c|c|c|c|c|}
\hline Boyut & Değişken & $\mathbf{N}$ & $\begin{array}{l}\text { Sira } \\
\text { Ortalaması }\end{array}$ & $\begin{array}{l}\text { Sira } \\
\text { Toplamı } \\
\end{array}$ & $\mathrm{U}$ & $\mathrm{p}$ \\
\hline \multirow{4}{*}{ Düşünme Stili } & Kadın & 61 & 109,11 & 6660.50 & \multirow[t]{2}{*}{2672.500} & \multirow[t]{2}{*}{.002} \\
\hline & Erkek & 122 & 83.41 & 10175.50 & & \\
\hline & Okul Müdürü & 92 & 86.95 & 7999.00 & \multirow[t]{2}{*}{3721.00} & \multirow[t]{2}{*}{.193} \\
\hline & Müdür Yardımcısı & 91 & 97.11 & 8837.00 & & \\
\hline
\end{tabular}

Tablo 4 incelendiğinde okul yöneticilerinin cinsiyetlerine göre düşünme stillerinde anlamlı bir farklılık olduğu görülmektedir ( $U=2672,5 ; p<.05)$. Bu farklılığın kadınlar lehine olduğu görülmektedir. Bu durum kadın okul yöneticilerinin erkek okul yöneticilerine göre baskın olarak bütüncül düşünme stiline sahip olmaları ya da erkek okul yöneticilerinin kadın okul yöneticilerine göre baskın olarak analitik düşünme stiline sahip oldukları anlamına gelmektedir. Bununla birlikte okul yöneticilerinin görevlerine göre düşünme stillerinde anlamlı bir farklılık bulunmamaktadır.

Okul yöneticilerinin çalıştıkları okul türüne göre düşünme stillerinde anlamlı bir farkın olup olmadığı Kruskall Wallis testi ile analiz edilerek ilgili sonuçlar Tablo 5'te gösterilmiştir. 
Okul Yöneticilerinin Analitik ve Bütüncül Düşünme Tarzlarına...

Tablo 5. Okul Yöneticilerinin Çalıştıkları Okul Türüne göre Düşünme Stilleri Puanlarının Karşılaştırılması

\begin{tabular}{lllllll}
\hline Boyut & Okul Türü & N & Ortalama Sıra & Sd & Kruskal Wallis H & p \\
\hline \multirow{3}{*}{ Düşünme Stili } & İlkokul & 66 & 103.90 & 2 & 5.268 & .072 \\
& Ortaokul & 51 & 86.10 & & & \\
& Lise & 66 & 84.66 & & & \\
\hline
\end{tabular}

Tablo 5 incelendiğinde okul yöneticilerinin çalıştıkları okul türlerine göre düşünme stilleri puanları arasında anlamlı bir fark olmadığı görülmektedir ( $\mathrm{H}=5.268 ; \mathrm{p}>.05)$.

Okul yöneticilerin kıdemlerine göre düşünme stili ortalama puanları arasında anlamlı bir fark olup olmadığını araştırmak için Kruskall Wallis analizi yapılmış ve ilgili bulgular Tablo 6' da gösterilmiştir.

Tablo 6. Okul Yöneticilerinin Kıdemlerin Göre Düşünme Stili Puanlarının Karşılaştırılması

\begin{tabular}{llllll}
\hline Boyut & K1dem & N & Ortalama Sira & Sd & Kruskal Wallis H \\
\hline \multirow{3}{*}{ Düşünme stili } & $1-5$ yil & 54 & 90.93 & 4 & .593 \\
& 6-10 yıl & 44 & 92.58 & & \\
& $11-15$ yil & 31 & 91.19 & & \\
& $16-20$ y1l & 25 & 87.40 & \\
\hline
\end{tabular}

Tablo 6 incelendiğinde okul yöneticilerinin kıdemlerine göre düşünme stillerinde anlamlı bir farkın olmadığı görülmektedir ( $\mathrm{H}=.593 ; \mathrm{p}>.05)$.

Okul yöneticilerinin cinsiyetlerine göre çatışma eylem stillerinde anlamlı bir farkın olup olmadığını araştırmak için bağımsız gruplar t testi yapılmıştır. Tablo 7'de ilgili bulgular gösterilmiştir.

Tablo 7.Okul Yöneticilerinin Cinsiyetlerine göre Çatışma Eylem Stillerinin Karşılaştırılması

\begin{tabular}{|c|c|c|c|c|c|c|c|}
\hline Değişken & Cinsiyet & $\mathbf{N}$ & $\bar{X}$ & Ss & sd & $t$ & $\mathrm{p}$ \\
\hline \multirow[t]{2}{*}{ Kaçınmacı } & Kadın & 61 & 2.94 & .62 & 181 & 2.095 & .038 \\
\hline & Erkek & 122 & 2.72 & .70 & & & \\
\hline \multirow[t]{2}{*}{ Zorlayıcı } & Kadın & 61 & 3.59 & .57 & 181 & 3.486 & .001 \\
\hline & Erkek & 122 & 3.25 & .63 & & & \\
\hline \multirow[t]{2}{*}{ Kolaylaştırıcı } & Kadın & 61 & 4.02 & .54 & 181 & 2.573 & .011 \\
\hline & Erkek & 122 & 3.79 & .57 & & & \\
\hline \multirow[t]{2}{*}{ Uzlaştırmacı } & Kadın & 61 & 3.44 & .66 & 181 & .417 & .677 \\
\hline & Erkek & 122 & 3.40 & .63 & & & \\
\hline \multirow[t]{2}{*}{ Karşı Koyucu } & Kadın & 61 & 3.71 & .62 & 181 & .641 & .522 \\
\hline & Erkek & 122 & 3.65 & .59 & & & \\
\hline
\end{tabular}

Tablo 7 incelendiğinde okul yöneticilerinin cinsiyetlerine göre kaçınmacı $(\mathrm{t}=2.095 ; \mathrm{p}<.05)$, zorlayıcı $(\mathrm{t}=3.486 ; \mathrm{p}<.05)$ ve kolaylaştıııcı $(\mathrm{t}=2.573 ; \mathrm{p}<.05)$ çatışma eylem stillerinde anlamlı bir farklılık olduğu görülmektedir. Bu bulguya göre kadın yöneticiler erkek yöneticilere göre çatışma durumlarında daha fazla kolaylaştıııcı, zorlayıcı ve kaçınması çatışma eylem stilini tercih etmektedirler. Bununla birlikte uzlaştırmacı $(\mathrm{t}=.417 ; \mathrm{p}>.05)$ ve karşı koyucu çatışma $(\mathrm{t}=.641 ; \mathrm{p}>.05)$ eylem stillerinde cinsiyete göre anlamlı bir fark bulunamamıştır.

Okul yöneticilerinin görevlerine göre çatışma eylem stillerinde anlamlı bir farkın olup olmadığını araştırmak için bağımsız gruplar t testi yapılmıştır. Tablo $8^{\prime}$ de ilgili bulgular gösterilmiştir.

Tablo 8. Okul Yöneticilerinin Görevlerine göre Çatışma Eylem Stillerinin Karşılaştırılması

\begin{tabular}{|c|c|c|c|c|c|c|c|}
\hline Değişken & Görev & $\mathbf{N}$ & $\bar{X}$ & Ss & sd & $\mathbf{t}$ & $\mathrm{p}$ \\
\hline \multirow[t]{2}{*}{ Kaçınmacı } & Müdür & 92 & 2.66 & .67 & 181 & -2.795 & .006 \\
\hline & Müdür Yardımcısı & 91 & 2.94 & .66 & & & \\
\hline \multirow[t]{2}{*}{ Zorlayıc1 } & Müdür & 92 & 3.36 & .60 & 181 & .058 & .954 \\
\hline & Müdür Yardımcısı & 91 & 3.35 & .66 & & & \\
\hline \multirow[t]{2}{*}{ Kolaylaştırıcı } & Müdür & 92 & 3.84 & .53 & 181 & -.644 & .521 \\
\hline & Müdür Yardımcısı & 91 & 3.89 & .61 & & & \\
\hline \multirow[t]{2}{*}{ Uzlaştırmacı } & Müdür & 92 & 3.42 & .57 & 181 & .034 & .973 \\
\hline & Müdür Yardımcısı & 91 & 3.41 & .71 & & & \\
\hline Karş1 Koyucu & Müdür & 92 & 3.64 & .57 & 181 & -.711 & .478 \\
\hline
\end{tabular}




$\begin{array}{llll}\text { Müdür Yardımcıs1 } & 91 & 3.71 & .63\end{array}$

Tablo 8 incelendiğinde okul yöneticilerinin yaptıkları görevlere göre kaçınmacı çatışma eylem stilinde anlamlı bir fark olduğu görülmektedir $(\mathrm{t}=-2.795 ; \mathrm{p}<.05)$. Bu bulgu, okul müdür yardımcılarının okul müdürlerine göre çatışmalarda kaçınmacı eylem stili daha fazla kullandıklarını işaret etmektedir. Zorlaştırıcı $(\mathrm{t}=.058 ; \mathrm{p}>.05)$, kolaylaştırıcı $(\mathrm{t}=-.644 ; \mathrm{p}>.05)$, uzlaştırmacı $(\mathrm{t}=.034 ; \mathrm{p}>.05)$ ve karşı koyucu $(\mathrm{t}=-.711 ; \mathrm{p}>.05)$ çatışma eylem stillerinde ise görev değişkenine göre anlamlı bir farkın olmadığı görülmektedir.

Okul yöneticilerinin kıdemlerine göre çatışma eylem stillerinde anlamlı bir farkın olup olmadığı araştırmak için tek yönlü varyans (ANOVA) analizi yapılmış ve sonuçlar Tablo 9'da gösterilmiştir.

Tablo 9. Okul Yöneticilerinin Çatışma Eylem Stillerinin Kıdemlerine göre Karşılaştırılması

\begin{tabular}{|c|c|c|c|c|c|c|c|c|c|c|}
\hline Değişken & Kidem & $\mathbf{N}$ & $\bar{X}$ & Ss & $\begin{array}{l}\text { Varyansın } \\
\text { Kaynağ1 }\end{array}$ & $\begin{array}{l}\text { Kareler } \\
\text { Toplamı }\end{array}$ & Sd & $\begin{array}{l}\text { Kare } \\
\text { Ortalamasi }\end{array}$ & $\mathbf{F}$ & $\mathbf{p}$ \\
\hline \multirow{5}{*}{ Kaçınmacı } & $1-5$ y1l & 54 & 2.87 & .62 & Gruplar arası & .480 & 4 & .120 & .253 & .908 \\
\hline & $6-10 \mathrm{y} 11$ & 44 & 2.77 & .68 & Grup içi & 84.509 & 178 & .475 & & \\
\hline & 11-15 y1l & 31 & 2.73 & .90 & Toplam & 84.989 & 182 & & & \\
\hline & $16-20 \mathrm{yil}$ & 25 & 2.78 & .43 & & & & & & \\
\hline & $\begin{array}{l}21 \text { yıl ve } \\
\text { üzeri }\end{array}$ & 29 & 2.77 & .71 & & & & & & \\
\hline \multirow{5}{*}{ Zorlayıcı } & $1-5$ yil & 54 & 3.37 & .55 & Gruplar arası & 1.471 & 4 & .368 & .909 & .460 \\
\hline & $6-10 \mathrm{y} 1 \mathrm{l}$ & 44 & 3.47 & .60 & Grup içi & 72.032 & 178 & .405 & & \\
\hline & $11-15$ y1l & 31 & 3.20 & .67 & Toplam & 73.503 & 182 & & & \\
\hline & $16-20 \mathrm{yll}$ & 25 & 3.40 & .69 & & & & & & \\
\hline & $\begin{array}{l}21 \text { yıl ve } \\
\text { üzeri }\end{array}$ & 29 & 3.31 & .72 & & & & & & \\
\hline \multirow{5}{*}{ Kolaylaştırıcı } & $1-5$ y1l & 54 & 3.94 & .56 & Gruplar arası & .662 & 4 & .165 & .495 & .739 \\
\hline & $6-10$ y1l & 44 & 3.85 & .53 & Grup içi & 59.415 & 178 & .334 & & \\
\hline & 11-15 y1l & 31 & 3.77 & .69 & Toplam & 60.077 & 182 & & & \\
\hline & $16-20 \mathrm{y} 1 \mathrm{l}$ & 25 & 3.92 & .56 & & & & & & \\
\hline & $\begin{array}{l}21 \text { yıl ve } \\
\text { üzeri }\end{array}$ & 29 & 3.82 & .54 & & & & & & \\
\hline \multirow{5}{*}{ Uzlaştırmacı } & $1-5$ y1l & 54 & 3.36 & .64 & Gruplar arası & .400 & 4 & .100 & .237 & .917 \\
\hline & $6-10$ yil & 44 & 3.40 & .56 & Grup içi & 75.033 & 178 & .422 & & \\
\hline & $11-15$ y1l & 31 & 3.44 & .77 & Toplam & 75.433 & 182 & & & \\
\hline & $16-20 \mathrm{yll}$ & 25 & 3.50 & .66 & & & & & & \\
\hline & $\begin{array}{l}21 \text { y1l ve } \\
\text { üzeri }\end{array}$ & 29 & 3.44 & .64 & & & & & & \\
\hline \multirow{5}{*}{ Karş1 Koyucu } & $1-5 \mathrm{y} 1 \mathrm{l}$ & 54 & 3.67 & .58 & Gruplar arası & 2.334 & 4 & .583 & 1.619 & .171 \\
\hline & $6-10$ yil & 44 & 3.65 & .59 & Grup içi & 64.153 & 178 & .360 & & \\
\hline & $11-15$ y1l & 31 & 3.52 & .66 & Toplam & 66.487 & 182 & & & \\
\hline & $16-20 \mathrm{yll}$ & 25 & 3.92 & .53 & & & & & & \\
\hline & $\begin{array}{l}21 \text { yıl ve } \\
\text { üzeri }\end{array}$ & 29 & 3.67 & .62 & & & & & & \\
\hline
\end{tabular}

Tablo 9 incelendiğinde okul yöneticilerinin kıdemlerine göre çatışma çözme eylem stillerinde anlamlı bir farkın olmadığı görülmektedir ( $\mathrm{F}=.253 ; \mathrm{F}=.909 ; \mathrm{F}=.495 ; \mathrm{F}=.237 ; \mathrm{F}=.171 ; \mathrm{p}>.05)$.

Okul yöneticilerin çalıştıkları okul kademesine göre çatışma eylem stillerinde bir fark olup olmadığı tek yönlü varyans analizi (ANOVA) ile incelenmiş ve sonuçlar Tablo 10'da gösterilmiştir.

Tablo 10. Okul Yöneticilerinin Çalıştıkları Okul Kademesine göre Çatışma Eylem Stillerinin Karşılaştırılması

\begin{tabular}{|c|c|c|c|c|c|c|c|c|c|c|}
\hline Değişken & Kidem & $\mathbf{N}$ & $\bar{X}$ & Ss & $\begin{array}{l}\text { Varyansın } \\
\text { Kaynağ1 }\end{array}$ & $\begin{array}{l}\text { Kareler } \\
\text { Toplamı }\end{array}$ & Sd & $\begin{array}{l}\text { Kare } \\
\text { Ortalaması }\end{array}$ & $\mathbf{F}$ & $\mathrm{p}$ \\
\hline & İlkokul & 66 & 2.76 & .76 & Gruplar arası & .382 & 2 & .191 & .406 & .667 \\
\hline & Ortaokul & 51 & 2.87 & .64 & Grup içi & 84.606 & .180 & .470 & & \\
\hline \multirow[t]{3}{*}{ Kaçınmacı } & Lise & 66 & 2.79 & .62 & Toplam & 84.989 & 182 & & & \\
\hline & İlkokul & 66 & 3.42 & .59 & Gruplar arası & .391 & 2 & .196 & .482 & .619 \\
\hline & Ortaokul & 51 & 3.33 & .68 & Grup içi & 73.112 & 180 & .332 & & \\
\hline \multirow[t]{3}{*}{ Zorlayıcı } & Lise & 66 & 3.32 & .64 & Toplam & 73.503 & 182 & & & \\
\hline & İlkokul & 66 & 3.92 & .59 & Gruplar arası & .307 & 2 & .154 & .462 & .631 \\
\hline & Ortaokul & 51 & 3.85 & .45 & Grup içi & 59.770 & 180 & .332 & & \\
\hline
\end{tabular}


Okul Yöneticilerinin Analitik ve Bütüncül Düşünme Tarzlarına...

\begin{tabular}{|c|c|c|c|c|c|c|c|c|c|c|}
\hline Kolaylaştırıcı & Lise & 66 & 3.82 & .78 & Toplam & 60.077 & 182 & & & \multirow[b]{2}{*}{.996} \\
\hline \multirow[b]{3}{*}{ Uzlaştırmacı } & İlkokul & 66 & 3.41 & .64 & Gruplar aras1 & .004 & 2 & .002 & \multirow[t]{2}{*}{.004} & \\
\hline & Ortaokul & 51 & 3.40 & .56 & Grup içi & 75.430 & 180 & .419 & & \\
\hline & Lise & 66 & 3.42 & .77 & Toplam & 75.433 & 182 & & & \\
\hline & İlkokul & 66 & 3.75 & .59 & Gruplar arası & .550 & 2 & .275 & .751 & .473 \\
\hline & Ortaokul & 51 & 3.63 & .59 & Grup içi & 65.937 & 180 & .366 & & \\
\hline Karşı Koyucu & Lise & 66 & 3.64 & .61 & Toplam & 66.487 & 182 & & & \\
\hline
\end{tabular}

Tablo 10 incelendiğinde okul yöneticilerinin çalıştıkları okul türüne göre çatışma eylem stillerinde anlamlı bir farkın olmadığı görülmektedir ( $\mathrm{F}=.406 ; \mathrm{F}=.482 ; \mathrm{F}=.462 ; \mathrm{F}=.237 ; \mathrm{F}=.751 ; \mathrm{p}>.05)$.

Okul yöneticilerinin düşünme stillerine göre çatışma eylem stillerinde bir fark olup olmadığını araştırmak için bağımsız gruplar t testi yapılmış ve bulgular Tablo 11'de gösterilmiştir.

Tablo 11. Okul Yöneticilerinin Düşünme Stillerine göre Çatışma Eylem Stillerinin Karşılaştırılması

\begin{tabular}{|c|c|c|c|c|c|c|c|c|c|}
\hline Değişken & Görev & $\mathbf{N}$ & $\overline{\bar{X}}$ & Ss & sd & $\mathbf{t}$ & p & $\begin{array}{l}\text { Etki Değeri } \\
\text { (Cohen's d) }\end{array}$ & $\begin{array}{l}\text { Etki } \\
\text { Boyutu } \\
\text { (r) }\end{array}$ \\
\hline \multirow[t]{2}{*}{ Kaçınmacı } & Bütünsel & 101 & 2.84 & .74 & 181 & -.993 & .322 & .148 & \\
\hline & Analitik & 82 & 2.74 & .60 & & & & & \\
\hline \multirow[t]{2}{*}{ Zorlayıcı } & Bütünsel & 101 & 3.43 & .64 & 181 & -1.680 & .095 & .250 & \\
\hline & Analitik & 82 & 3.27 & .61 & & & & & \\
\hline \multirow[t]{2}{*}{ Kolaylaştırıcı } & Bütünsel & 101 & 3.98 & .53 & 181 & -3.170 & .002 & .471 & .26 \\
\hline & Analitik & 82 & 3.72 & .59 & & & & & \\
\hline \multirow[t]{2}{*}{ Uzlaştırmacı } & Bütünsel & 101 & 3.53 & .55 & 181 & -2.856 & .005 & .425 & .21 \\
\hline & Analitik & 82 & 3.27 & .71 & & & & & \\
\hline \multirow[t]{2}{*}{ Karşı Koyucu } & Bütünsel & 101 & 3.73 & .60 & 181 & -1.518 & .131 & .226 & \\
\hline & Analitik & 82 & 3.60 & .59 & & & & & \\
\hline
\end{tabular}

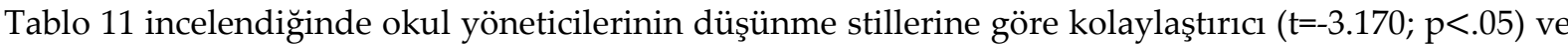

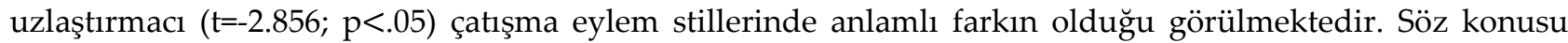
anlamlı farkın her iki çatışma eylem stilinde de bütünsel düşünen okul yöneticileri lehine olduğu görülmektedir. Ortalamalar arasındaki farkların büyüklüğünün etki değeri orta büyüklüktedir $(\mathrm{d}=.5)$. Bu bulgu, bütüncül düşünen okul yöneticilerinin analitik düşünen okul yöneticilerine göre çatışmalarda daha çok uzlaşmacı ve kolaylaştırıcı çatışma eylem stilini kullandıklarını ifade etmektedir. Bununla beraber kaçınmacı $(\mathrm{t}=-.993 ; \mathrm{p}>.05)$, zorlayıcı $(\mathrm{t}=.095 ; \mathrm{p}>.05)$ ve karşı koyucu $(\mathrm{t}=.131 ; \mathrm{p}>.05)$ çatışma eylem stillerinde düşünme tarzına göre anlamlı bir farkın olmadığı görülmektedir.

Okul yöneticilerinin düşünme stilleri ile çatışma eylem stilleri arasındaki ilişkinin incelenmesi için Pearson Çarpım Moment korelasyon katsayısı hesaplanmış ve ilgili bulgular Tablo 12'de gösterilmiştir.

Tablo 12. Okul Yöneticilerinin Düşünme Stilleri ile Çatışma Eylem Stilleri Arasındaki İlişki

\begin{tabular}{|c|c|c|c|c|c|c|}
\hline Değişken & Kaçınmacı & Zorlayıı & Kolaylaştırıcı & Uzlaştırmacı & Karşı Koyucu & $\begin{array}{l}\text { Düşünme } \\
\text { Stili }\end{array}$ \\
\hline Kaçınmacı & $\mathrm{R}$ & .170 & $.367^{* *}$ & $.517^{* *}$ & -.012 & .0074 \\
\hline Zorlayıcı & $\mathrm{R}$ & & .415 & .286 & $.327^{* *}$ & .124 \\
\hline Kolaylaştırıcı & $\mathrm{R}$ & & & $.581^{* *}$ & .313 & $.229^{* *}$ \\
\hline Uzlaştırmacı & $\mathrm{R}$ & & & & .161 & $.208^{* *}$ \\
\hline Karşı Koyucu & $\mathrm{R}$ & & & & & .112 \\
\hline
\end{tabular}

Tablo 12 incelendiğinde düşünme stilleri ile kolaylaştırıcı ve uzlaştırmacı çatışma eylem stilleri arasında pozitif yönde düşük düzeyde ilişki olduğu görülmektedir ( $\mathrm{r}=.229 ; \mathrm{p}<.001, \mathrm{r}=.208 ; \mathrm{p}<.001)$. Bu durum okul yöneticilerinin bütüncül düşünme düzeyleri arttıkça kolaylaştırıcı ve uzlaştırmacı çatışma eylem stillerini kullanma eğilimlerinin de artacağı şeklinde yorumlanabilir. Bununla birlikte kaçınmacı çatışma eylem stili ile kolaylaştırıcı çatışma eylem stili arasında pozitif yönde orta düzeyde $(r=.367 ; p<.001)$ ve uzlaştırmacı çatışma eylem stili ile pozitif yönde yüksek düzeyde $(\mathrm{r}=.517, \mathrm{p}<.001)$ ilişki olduğu görülmüştür. Zorlayıcı çatışma 
eylem stili ile kaçınmacı çatışma eylem stili ile pozitif yönde orta düzeyde $(\mathrm{r}=.327 ; \mathrm{p}<.001)$ ve kolaylaştırıcı çatışma eylem stili ile uzlaştırmacı çatışma eylem stili ile pozitif yönde yüksek düzeyde $(\mathrm{r}=.581, \mathrm{p}<.001)$ ilişki olduğu görülmüştür.

\section{Tartışma ve Sonuç}

Bu çalışmada okul yöneticilerinin düşünme tarzları ile çatışma çözme eylem stilleri arasındaki ilişkiler araştırılmıştır. Çalışmanın sonucunda okul yöneticilerinin çoğunun bütüncül düşünme stiline sahip oldukları görülmektedir. Bütüncül düşünme stili, kişilerarası ilişkiler, geçmiş deneyimler ve duygusallıkla bağlantılıdır (Epstein, 2008). Kültürel olarak bakıldığında toplumsal kültürün baskın olduğu toplumlarda bütünsel düşüncenin baskın olacağı ön görülmektedir (Choi ve diğerleri 2007). Türk Toplumunun toplumsal kültür ögelerini daha çok taşıdığı söylenebilir (Hofstede, 1980). Bununla birlikte çalışmanın sonucunda kadın okul yöneticilerinin bütüncül, erkek okul yöneticileri ise analitik düşünme tarzına sahip olduğu görülmüştür. Bu durumun nedenlerinden birinin, kadınların genellikle irrasyonel veya aşırı duygusal olarak kalıplaşmış, toplumsal cinsiyet rollerini benimsemiş olmaları olduğu söylenebilir (Blackstone, 2003).

Okul yöneticilerinin kıdem ve görevlerine göre düşünme tarzlarında bir farklılık yoktur. Bu durum yıllar geçtikçe ya da yönetimde hiyerarşik olarak üst roller üstlendikçe düşünme tarzlarında anlamlı bir farklılık olmayacağ şeklinde yorumlanabilir. İlkokulda çalışan okul yöneticilerinin ortaokul ve lisede çalışan okul yöneticilerine göre daha bütüncül düşündüğü görülmüştür. Sünbül (2004) detaylarla ilgilenmemeyi, genel konular üzerinde genel bir çerçevede düşünceleri ifade etmeyi bütüncül düşünmenin özellikleri olarak sıralamaktadır. Balgamış ve Baloğlu (2010) ortaöğretimde yönetici olan okul yöneticilerinin ilköğretimde çalışan okul yöneticilerine göre daha çok bütüncül düşündüklerini belirtmektedir. Bu bulgu çalışma bulgusunu desteklememektedir.

Okul yöneticilerinin en çok kullandığı çatışma eylem stilinin kolaylaştırıcı çatışma eylem stili olduğu görülmüştür. Okul yöneticilerinin kolaylaştırıcı çatışma eylem stilini en yüksek düzeyde tercih etmeleri, çatışma durumlarında karşı tarafın isteklerini önceleyen bir yaklaşım sergilediklerini ifade etmektedir. Bunu sırasıyla uzlaştırmacı, karşı koyucu, zorlayıcı ve kaçınmacı çatışma eylem stilleri takip etmektedir. Yapılan çalışmalara bakıldığında, öğretmenler okul yöneticilerinin en yüksek düzeyde karşı koyucu ve uzlaşmacı çatışma çözme stillerini kullandıklarını belirtmektedirler (Arslantaş ve Özkan, 2012; Çimen ve Sarıboğa, 2020; Kaya ve Yılmaz, 2015; Yüksel, 2020). Okul yöneticileri de uzlaşmacı ve karşı koyucu çatışma çözme stillerini en yüksek düzeyde kullandıklarını dile getirmişlerdir (Çimen ve Sarıboğa, 2020; Maral, 2016; Yıldızoğlu ve Burgaz, 2014; Yüksel, 2020). Bu bulgular kısmen çalışma bulgusunu desteklemektedir.

Kadın okul yöneticilerinin erkek okul yöneticilerine göre daha çok kaçınmacı, zorlayıcı ve kolaylaştırıcı eylem stillerini kullandıkları görülmüştür. Kaçınmacı çatışma eylem stili genellikle uyumu sürdürmenin önemsendiği doğu kültürlerinde yaygındır (Huang, 1999). Dolayısıyla bütüncül düşünen bireylerin çatışma çözmede kaçınmacı stili benimsemesi beklenmektedir. Kadın okul yöneticilerinin erkek okul yöneticilerine göre daha bütüncül düşündüğü göz önüne alındığında; kadın okul yöneticilerinin kaçınmacı çatışma eylem stilini daha çok tercih etmeleri açıklanabilir olmaktadır. Kadın yöneticilerin erkek yöneticilere göre daha çok kolaylaştırıcı ve zorlayıcı çatışma eylem stilini tercih etmesi, ataerkil bir toplumda kendini kabul ettirmenin bir tezahürü olarak yorumlanabilir. Kadın okul yöneticisi, kendini kabul ettirmek için çatışmalarda kendi isteklerinden vazgeçmek ve kendi isteklerinde diretmek gibi iki uç tutum sergileyerek, erkek hegemonyasının baskın olduğu yönetim kademelerinde kendini var etmenin radikal yollarını tercih ediyor olabilir. Bununla birlikte bir örgütte zorlayıcı çatışma eylem stilini kullanmak, örgüt çalışanlarının performansının düşmesine neden olacaktır (Cohen ve Bailey, 1997).

Okul müdür yardımcılarının okul müdürlerine göre daha çok kaçınmacı çatışma eylem stilini kullandıkları görülmüştür. Bununla birlikte okul yöneticilerinin görevlerine göre zorlaştırıcı, kolaylaştırıcı, uzlaştırmacı ve karşı koyucu çatışma eylem stillerinde anlamlı bir farklılık bulunmamıştır. Müdür yardımcılığı geleneksel olarak "bakıc1-yönetici” olarak tanımlanmıştır (Koru, 1993). Porter (1996), müdür yardımcılarını açıkça belirlenmiş iş tanımları olmayan günlük operasyon yöneticileri olarak tanımlamıştır. 
Marshall ve Mitchell (1991), müdür yardımcılarının görev sorumluluklarının genellikle müdür tarafından tayin edildiğini belirtmişlerdir. Müdür yardımcılarının görev tanımlarındaki bu durum, okul müdürlerine göre kaçınmacı çatışma eylem stilini daha çok kullanmalarını açıklamaktadır.

Bütüncül düşünen okul yöneticilerinin analitik düşünen okul yöneticilerine göre daha çok kolaylaştırıcı ve uzlaştırıcı çatışma çözme eylem stillerini kullandıkları görülmüştür. Analitik düşünenlerin, davranışın bağlamsal belirleyicilerini görmezden geldikleri ve bir olayın nedenselliğini sürekli olarak nesneye veya bireye atadıkları gösterilmiştir (Miller, 1984). Bunun aksine, alana odaklanma eğiliminde olan bütünsel düşünürler, dış bağlamsal etkileri de davranışın önemli belirleyicileri olarak görürler. Dolayısıyla bütüncül düşünen okul yöneticileri ilişkilerin sürdürülebilirliğini sağlamak için ya tamamen ya da kısmen kişisel isteklerinden vazgeçerek yaşanan çatışmaları çözme yoluna gitmeyi tercih etmektedirler. Uzlaşmacı çatışma eylem stilini kullanmanın en büyük yararı, çatışmanın kısa sürede çözülebilmesidir. Fakat bu çatışma eylem stilini fazla kullanmak, her durumda çatışmanın çözülebilmesi için tarafların arzularının yerine getirilmesi zorunluluğunun oluşmasıdır (Lussier, 2010). Deneyimler, yöneticilerin bir çatışmada çözüm için geliştirecekleri stratejiler için repertuvar sağlarlar. Bununla birlikte Tzu (2008) başarıya götüren yöntemin, tekrar kullanılmadan önce yeni bağlama göre düzenlenmesi gerektiği tavsiyesinde bulunmuştur. Dolayısıyla bütüncül düşünen okul yöneticileri, geçmiş deneyimlerine ve duygularına dayanarak çatışmayı kısa sürede bitirmek ya da çatışma çözümü için karşılıklı fedakarlıkta bulunma eğiliminde olabilirler. Okul yöneticilerinin düşünme tarzları ile çatışma eylem stilleri arasındaki ilişkilere bakıldığında, bütüncül düşünme düzeyi artııça kolaylaştırıcı ve uzlaştırıcı çatışma eylem stillerini kullanma düzeylerinin arttığı görülmektedir. Başka bir ifade ile okul yöneticileri analitik düşünmeye başladıkça çatışmalarda uzlaşmacı ya da kolaylaştırıcı olmayı tercih etmemektedir. Analitik düşünen bireyler, çatışma durumunda yeterli veri toplar ve düşünce süreçlerini topladıkları verilere dayandırırlar. Tüm bu süreç sonunda elde ettikleri çıkarım ve sonuçlara göre de karar verirler (Parlar, 2016). Dolayısıyla böyle bir düşünce stiline sahip olmak çatışmalarda tek taraflı ya da karşılıklı vazgeçişi temel alan çatışma eylem stili olan kolaylaştııııı ve uzlaştırıcı olmayı zorlaştıracaktır. Daha bütüncül düşünen bireyler, çatışmaya neden olan durumdan çok olayı, çatışma tarafları ile yaşanan ilişkiler bağlamında değerlendirdiğinden, çatışmaya neden olan sorunun çözümü yerine sürdürülebilir ilişkilere odaklanarak kolaylaştırıcı ve uzlaştırıcı çatışma eylem stilini benimsiyor olabilirler.

Okul yöneticilerinin çatışmalara yaklaşımı örgütün gelişimi açısından büyük önem taşımaktadır. Çatışma çözme

Araştırma sonuçları doğrultusunda uygulayıcılara aşağıdakiler önerilmektedir:

- $\quad$ Okul yöneticilerinin baskın olarak bütüncül düşünme stiline sahip oldukları görülmektedir. Gelişim alanı olarak analitik düşünme becerilerini geliştirmeleri önerilebilir. Okul yöneticilerinin daha analitik düşünme becerisine sahip olmaları, uzun vadede çatışma çözümlerinin örgütsel olarak olumlu çıktılar vermesini sağlayacaktır. Bu nedenle okul yöneticilerine analitik düşünme becerilerini geliştirecek hizmet içi eğitim uygulamalarının planlanması önerilmektedir.

- Çatışma çözümlerinde kullanılan her yöntemin işe yaradığı özel durumların olduğu bilinmektedir. Dolayısıyla okul yöneticileri çatışmalara yaklaşımlarında yalnızca geçmiş deneyimleri ya da kişilik özelliklerini önceleyerek bir yöntem belirlemek yerine, hangi çatışma eylem stilinin hangi durumlarda işe yarayacağı konusunda bilgi sahibi olmalıdır. Bu bağlamda okul yöneticilerine çatışma çözme teknikleri konusunda hizmet içi eğitim uygulamalarının planlanması önerilmektedir.

- $\quad$ Okul yöneticilerinin baskın olarak bütüncül düşündüğü görülmüştür. Bu durum çatışma çözmede büyük oranda deneyimlerinden faydalandıklarını göstermektedir. Deneyim zenginliği sağlaması açısından bölgelerindeki diğer okul yöneticileriyle çatışma çözme deneyimlerini paylaşabilecekleri kohort grupları oluşturmaları önerilmektedir.

- CÇatışmalar olumlu çözüldügüünde taraflara olumlu kazanımlar sağlamaktır. Bu olumlu sonuçlar örgütün gelişmesini de beraberinde getirmektir. Bu bağlamda okul yöneticilerinin çatışma çözme konusunda farkındalığının artması adına "yönetimde iyi örnekler" konulu çalıştay, sempozyum ve konferansların düzenlenmesi önerilmektedir. 
Araştırmacılara öneriler ise aşağıdaki gibidir:

- Okul yöneticilerinin çatışma çözme yaklaşımları ile karar verme biçimleri arasındaki ilişkiler incelenebilir.

- $\quad$ Okul yöneticilerinin düşünme stillerini etkileyen kültürel faktörler incelenebilir.

- $\quad$ Okul yöneticilerinin düşünme stillerini daha derinden incelemek için karma desenli bir çalışma yapilabilir.

\section{Yazar(lar)ın Beyanı}

Araştırmacıların katkı oranı beyanı: Çalışma için araştırmacılar eşit katkıda bulunmuştur.

Etik Kurul Kararı: Araştırma Mimar Sinan Güzel Sanatlar Üniversitesi 24.12.2020 tarih 10130 sayıl Etik Kurul kararınca uygun bulunmuştur.

Çatışma beyanı: Herhangi bir çıkar çatışması bulunmamaktadır.

Destek ve teşekkür: Araştırmada destek alınmamıştır.

\section{Kaynaklar}

Alagözlü, N. (2017). Cross cultural conflict resolution styles: Data revisited. International Online Journal of Education and Teaching, 4(3), 199-211.

Apanovich, V. V., Bezdenezhnykh, B. N., Sams, M., Jääskeläinen, I. P., \& Alexandrov, Y. (2018). Event-related potentials during individual, cooperative, and competitive task performance differ in subjects with analytic vs. holistic thinking. International journal of Psychophysiology, 123, 136-142.

Arslantaş, H. İ. \& Özkan, M. (2012). İlköğretim okullarında görev yapan öğretmenlerin görüşlerine göre okul müdürlerinin çatışma yönetimi yaklaşımlarının incelenmesi. Kastamonu Eğitim Dergisi, 20(2), 555-570.

Anthony, B. P., Scott, P., \& Antypas, A. (2010). Sitting on the fence? Policies and practices in managing humanwildlife conflict in Limpopo Province, South Africa. Conservation and Society, 8(3), 225-240.

Balgamış, E., \& Baloğlu, M. (2010). Eğitim yöneticilerinin düşünme stilleri açısından çeşitli değişkenlere göre incelenmesi. Hacettepe Üniversitesi Ĕ̆itim Fakültesi Dergisi, 38(38), 1-10.

Berscheid, E., Walster, E., \& Barclay, A. (1969). Effect of time on tendency to compensate a victim. Psychological Reports, 25(2), 431-436.

Blackstone, A. (2003). Gender roles and society. In Julia R. Miller, Richard M. Lerner, and Lawrence B. Schiamberg (Ed). Human ecology: An encylopedia of children, families communities, and environments (pp. 335-338). Santa Barbara, CA: ABC CLIO.

Burton, J. W. (1990). Conflict resolution. St. Martin's Press

Choi, I., Koo, M., \& Choi, J. A. (2007). Individual differences in analytic versus holistic thinking. Personality and Social Psychology Bulletin, 33(5), 691-705.

Çıimen, L. K., \& Sarıboğa, F. B. (2020). Okul müdürlerine ve öğretmenlerin algılarına göre çatışma yönetimi stillerinin bazı değişkenler açısından incelenmesi. Akademik Sosyal Araştırmalar Dergisi,8 (110), 29-55. http://dx.doi.org/10.29228/ASOS.46171

Darling, J. R., \& Walker, W. E. (2001). Effective conflict management: use of the behavioral style model. Leadership \& Organization Development Journal.

Deutsch, M. (1973). The resolution of conflict: Constructive and destructive processes. Yale University Press.

Epstein, S. (1994). Integration of the cognitive and the psychodynamic unconscious. American Psychologist, 49(8), 709-724.

Epstein, J. M. (2008). Why model?. Journal of Artificial Societies and Social Simulation, 11(4), 12. 
Hammer, N. (2005). International framework agreements: Global industrial relations between rights and bargaining. Transfer: European Review of Labour and Research, 11(4), 511-530.

Hofstede, G. (1980). Culture and organizations. International Studies of Management \& Organization, 10(4), 1541.

Huan, L. J., \& Yazdanifard, R. (2012). The difference of conflict management styles and conflict resolution in workplace. Business \& Entrepreneurship Journal, 1(1), 141-155.

Huang, L. L. (1999). Interpersonal harmony and conflict: Indigenous theory and research. Laurel.

İnand1, Y., Tunç, B., \& Gündüz, B. (2013). Okul yöneticilerinin özyeterlik algıları ile çatışmayı çözme stratejileri arasındaki ilişki. Kuram ve Uygulamada Ĕ̆itim Yönetimi Dergisi, 19(2), 275-294.

Johnson, D. W., \& Johnson, F. P. (2008). Joining together: Group theory and group skills. Allyn \& Bacon.

Karadağ, E. ve Tosun, Ü. (2014). Çatışma eylem stilleri ölçeği [ÇESÖ]: Türkçe'ye uyarlanması dil geçerliği ve ön psikometrik incelemesi. Psikoloji Çalı̧̧maları, 34(1), 45-69.

Karakuş, M. \& Çankaya, İ. H. (2009). Okul yöneticilerinin kişilik özelliklerinin çatışma çözme stratejileri üzerindeki etkisi. Adıyaman Üniversitesi Sosyal Bilimler Enstitüsü Dergisi, (3), 111-118.

Karasar, N. (2003). Bilimsel araştırma yöntemi. Nobel Yayın Dağıtım.

Kavak, B., Sunaoğlu, Ş. K., \& Taner, N. (2017). Yeniliği benimseyen kategorilerin bütüncül ve analitik düşünme açısından farklılıkları: Akıllı telefonlar için bir inceleme. Pazarlama ve Pazarlama Araştırmaları Dergisi, 20, $179-200$.

Kaya, A. \& Yılmaz, S. (2015). Çatı̧̧mayı yönetme stilleri ile müzakere becerileri arasındaki ilişki. C.Ü. İktisadi ve İdari Bilimler Dergisi, 16(2), 145-160.

Kılıç, S. (2014). Etki büyüklüğü. Journal of Mood Disorders, 4(1), 44-6. DOI: 10.5455/jmood.20140228012836

Koru, J. M. (1993). The assistant principal: crisis manger, custodian, or visionary?, NASSP Bulletin, 77 (556), 6771

Lussier, R.N. (2010). Human relations in organizations: applications and skill building. Mc Graw Hill/Irwin.

Maral, M. (2016). Okul yöneticilerinin liderlik stilleri ile çatışma çözme stratejileri arasındaki ilişki. [Yayımlanmamış Yüksek Lisans Tezi], Sakarya Üniversitesi.

Mızrak, C. (2019). Hemşirelere yönelik psikolojik şiddet ve çatışma eylem stilleri arasındaki ilişki [Yayımlanmamış Yüksek Lisans Tezi]. Ordu Üniversitesi.

Miller, J. G. (1984). Culture and the development of everyday social explanation. Journal of Personality and Social Psychology, 46(5), 961-978.

Monga, A. B., \& John, D. R. (2007). Cultural differences in brand extension evaluation: The influence of analytic versus holistic thinking. Journal of Consumer Research, 33(4), 529-536.

Nisbett, R. E., Peng, K., Choi, I., \& Norenzayan, A. (2001). Culture and systems of thought: Holistic versus analytic cognition. Psychological Review, 108(2), 291-310.

Nisbett, R. E., \& Masuda, T. (2003). Culture and point of view. Proceedings of the National Academy of Sciences, 100(19), 11163-11170.

Öksüz, Y. \& Öztürk, M. B. (2016). Öğretmen adaylarının çatışma eylem stilleri ile kültürlerarası duyarlılık düzeyleri arasındaki ilişki. Manas Sosyal Araştırmalar Dergisi, 5(4), 1-12.

Özdemir, A. Y. \& Özdemir, A. (2007). Duygusal zekâ ve çatışma yönetimi stratejileri arasındaki ilişkilerin incelenmesi: üniversitede çalışan akademik ve idari personel üzerine uygulama. Selçuk Üniversitesi Sosyal Bilimler Enstitüsü Dergisi, (18), 393-410. 
Parlar, H. (2016). Sınıf öğretmenlerinin kritik ve analitik düşünme becerilerinin-eğilimlerinin incelemesi: İstanbul Ümraniye örneği. İstanbul Ticaret Üniversitesi Sosyal Bilimler Dergisi, 15 (1), 45-72.

Rafique, A., Habib, H., Rehman, F. A., \& Arshi, S. (2020). Impact of rational and experiential thinking styles on interpersonal conflict resolution among young adults. Journal of Mind and Medical Sciences, 7(1), 6978.

Rahim, M. A., Antonioni, D., \& Psenicka, C. (2001). A structural equations model of leader power, subordınates'styles of handling conflict, and job performance. International Journal of Conflict Management, 12(3),191-211.

San Martin, A., Schug, J., \& Maddux, W. W. (2019). Relational mobility and cultural differences in analytic and holistic thinking. Journal of Personality and Social Psychology, 116(4), 495-518. https://doi.org/10.1037/pspa0000142

Shapiro, D., Pilsitz, L., \& Shapiro, S. (2004). Conflict and communication: a guide through the labyrinth of conflict management. IDEA.

Stevenson, H. W., \& Stigler, J. W. (1992). The learning gap: Why our schools are failing and what can we learn from Japanese and Chinese education. Summit Books.

Sünbül, A. M. (2004). Düşünme stilleri ölçeğinin geçerlik ve güvenirliği. Eğitim ve Bilim, 29(132), 25-42.

Tabachnick, B. G., and Fidell, L. S. (2013). Using multivariate statistics (Sixth edition). Pearson Education

Tekin, M., Özmutlu, İ., \& Erhan, S. (2009). Özel yetenek sınavlarına katılan öğrencilerin karar verme ve düşünme stillerinin incelenmesi. Atabesbd, 11(3), 42-56.

Thakore, D. (2013). Conflict and conflict management. IOSR Journal of Business and Management (IOSR$J B M), 8(6), 07-16$.

Tracy, L., \& Johnson, T. W. (1981). What do the role conflict and role ambiguity scales measure?. Journal of Applied Psychology, 66(4), 464-469. https://doi.org/10.1037/0021-9010.66.4.464

Tzu, S. (2008). Savaş sanatı: savaşmadan kazanmak doktrini ekonomist ve politikacılara yol gösteren eser. (Çev. Adil Demir). Kastaş Yayınevi.

Umay, A., \& Arıol, Ş. (2011). Baskın olarak bütüncül stilde düşünenlerle baskın olarak analitik stilde düşünenlerin problem çözme davranışlarının karşılaştırılması. Pamukkale Üniversitesi Ĕ̆itim Fakültesi Dergisi, 30(30), 27-37.

Yıldızoğlu, H., \& Burgaz, B. (2014). Okul yöneticilerinin beş faktör kişilik özellikleriyle çatışma yönetimi stili tercihleri arasındaki ilişki. Hacettepe Üniversitesi Ĕ̆itim Fakültesi Dergisi, 29(2), 295-310.

Yuan, W. (2010). Conflict management among American and Chinese employees in multinational organizations in China. Cross Cultural Management: An International Journal. 17(3), 287-372.

Yüksel, Y. M. (2020). Okul müdürlerinin çatışma yönetim stillerinin öğretmen motivasyonu açısından incelenmesi. [Yayımlanmamış Yüksek Lisans Tezi], Pamukkale Üniversitesi. 


\section{EXTENDED ABSTRACT}

\section{Introduction}

In Turkey, school administrators work as school principals and assistant principals. School administrators undertake many roles and responsibilities due to their job descriptions. School administrators are expected not only to manage their schools but also to lead changes in line with the needs of the age. It is obvious that where there is change, there will also be conflict. When people with different values in the organization interact with each other, situations that create tension can arise. Therefore, conflict is seen as a situation in which two or more people working in an organization cannot agree (Darling and Walker, 2001). Conflict resolution approaches of school administrators are important in terms of maintaining the team spirit they need to create while managing the school in accordance with its purpose. As in every organization, conflicts arise between people for various reasons in educational organizations. Scott (2010) listed some of the problems that may cause conflict in an organization as communication (non-communication), employee attitudes, honesty, disobedience, treating others, and work habits. In these and many similar situations, school administrators may exhibit a different conflict resolution approach.

Holistic thinking is attributed to the East Asian culture, where the culture of collectivism is intense. Holistic thinking is a thinking orientation that includes paying attention to the relationships between the focal object and the area it is in, explaining and predicting events by considering such relationships, and evaluating the event as a whole in a context (Nisbett et al., 2001). The main characteristic of holistic thinkers is the tendency to evaluate events and objects in the context in which they are presented. Seeing the world as a complex structure of interactions, relationships, and all exchanges and paying attention to the connections between events are the elements considered in the solution of an issue approached from a holistic perspective (Apanovich, Bezdenezhnykh, Jääskeläinen, and Alexandrov, 2018).

Analytical thinking, on the other hand, is attributed to the Western culture, where the culture of individualism is at the forefront. Analytical thinking is a style of thinking that includes the tendency to categorize the focal object, taking into account the characteristics of the object in question, and taking the object out of its context and also the tendency to explain and predict the behavior of the object by using the rules of the categories (Nisbett et al., 2001). Therefore, individuals with an analytical thinking style have beliefs that the world is separate and discontinuous, and that the behavior of an object can be predicted using rules and characteristics (Monga and John, 2007). In this respect, unlike individuals with a holistic thinking style, analytical thinkers tend to see events and objects primarily change according to their own rules and do not change over time, rather than interacting with their environment (Nisbett and Masuda, 2003).

\section{Method}

This research was designed in the relational screening model. The study group of the research consists of 183 school administrators. Conflict Action Styles Scale and Analytical and Holistic Thinking Scale were used as data collection tools in the research. Data were analyzed with the SPSS24 software.

\section{Results}

The research concluded that most school administrators have a holistic thinking style. Observations revealed that the conflict action style most used by school administrators was the facilitating conflict action style. Observations also revealed that holistic thinking school administrators used more facilitating and conciliatory conflict resolution action styles than analytical thinking school administrators. There is no difference in the way of thinking of school administrators according to their seniority and duties. Assistant principals were observed to use conflict avoidance action style more than school principals. Female school administrators were observed to use avoidant, coercive, and facilitating action styles more than male school administrators.

\section{Conclusion}

The results of the research reveal that most school administrators have a holistic thinking style. The 
holistic thinking style is related to interpersonal relations, past experiences, and emotionality (Epstein, 2008). From a cultural point of view, it is predicted that holistic thinking will prevail in societies where social culture is dominant (Choi, Koo, and Choi, 2007). It is possible to indicate that Turkish society has more collective cultural elements (Hofstede, 1980). Nevertheless, the study concluded that female school administrators had a holistic thinking style and male school administrators had an analytical thinking style. It is possible to mention that one of the reasons for this state is that women generally adopt stereotyped social gender roles as irrational or overly emotional (Blackstone, 2003).

Observations revealed that the conflict action style most used by school administrators was the facilitating conflict action style. The fact that school administrators prefer the facilitating conflict action style at the highest level indicates that they show an approach that prioritizes the wishes of the other party in conflict situations. This is followed by conciliatory, oppositional, coercive, and avoidant conflict action styles, respectively.

The study exhibited that holistic thinking school administrators used more facilitating and conciliatory conflict resolution action styles than analytical thinking school administrators. The study also showed that analytical thinkers ignore the contextual determinants of behavior and consistently assign the causality of an event to an object or individual (Miller, 1984). In contrast, holistic thinkers, who tend to focus on the field, see external contextual influences also as important determinants of behavior. Therefore, school administrators, who think holistically, prefer to resolve the conflicts by giving up their wishes, either completely or partially, to ensure the sustainability of relationships. The greatest benefit of using the conciliatory conflict action style is that the conflict can be resolved in a short time. However, using this conflict action style excessively means the necessity of fulfilling the wishes of the parties in any case to resolve the conflict (Lussier, 2010).

An examination of the relationships between school administrators' thinking styles and conflict action styles reveals that as the level of holistic thinking increases, the level of use of facilitating and conciliatory conflict action styles increases. In other words, as school administrators start to think analytically, they do not prefer to be a conciliator or facilitator in conflicts. Analytical thinking individuals collect sufficient data in conflict situations and base their thought processes on the data they collect. At the end of this whole process, they decide according to the inferences and results they have obtained (Parlar, 2016). Therefore, having such a thinking style will make it difficult to be a facilitator and conciliator, which is a conflict action style based on unilateral or mutual renunciation. Since individuals who think more holistically evaluate the event in the context of relations with the conflict parties rather than the situation that caused the conflict, they may adopt a facilitating and conciliatory conflict action style by focusing on sustainable relations instead of solving the problem causing the conflict. 